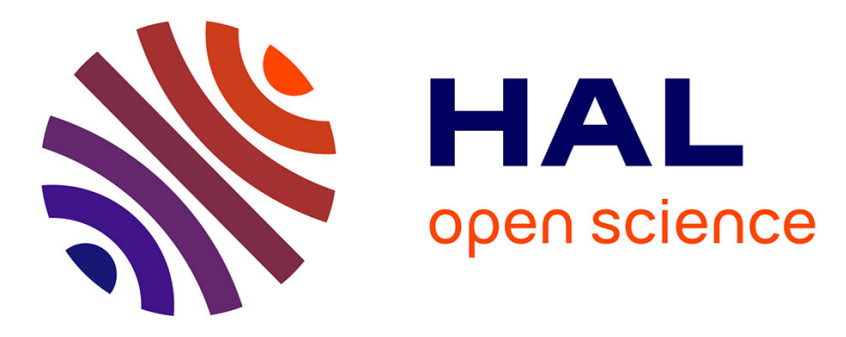

\title{
Values of diagnostic tests for the various species of spirochetes
}

Carole Eldin, Benoît Jaulhac, Oleg Mediannikov, Jean-Pierre Arzouni, Didier Raoult

\section{- To cite this version:}

Carole Eldin, Benoît Jaulhac, Oleg Mediannikov, Jean-Pierre Arzouni, Didier Raoult. Values of diagnostic tests for the various species of spirochetes. Médecine et Maladies Infectieuses, 2019, 49 (2), pp.102-111. 10.1016/j.medmal.2019.01.009 . hal-02262539

\section{HAL Id: hal-02262539 \\ https://hal-amu.archives-ouvertes.fr/hal-02262539}

Submitted on 22 Oct 2021

HAL is a multi-disciplinary open access archive for the deposit and dissemination of scientific research documents, whether they are published or not. The documents may come from teaching and research institutions in France or abroad, or from public or private research centers.
L'archive ouverte pluridisciplinaire HAL, est destinée au dépôt et à la diffusion de documents scientifiques de niveau recherche, publiés ou non, émanant des établissements d'enseignement et de recherche français ou étrangers, des laboratoires publics ou privés.

\section{(ㄷ)(1) $\$$}

Distributed under a Creative Commons Attribution - NonCommercial| 4.0 International 


\section{Performances des tests diagnostiques pour les différentes espèces de spirochètes}

\section{Values of diagnostic tests for the various species of spirochetes}

Carole Eldin $^{1}$, Benoit Jaulhac ${ }^{2}$, Oleg Mediannikov ${ }^{1}$, Jean-Pierre Arzouni ${ }^{3}$, Didier Raoult ${ }^{4}$

${ }^{1}$ Aix Marseille Univ, IRD, AP-HM, SSA, VITROME, IHU-Méditerranée Infection, Marseille, France

2 Centre National de Référence des Borrelia, laboratoire de bactériologie, Hôpitaux Universitaires de Strasbourg \& Faculté de Médecine de Strasbourg

${ }^{3}$ Plate-forme de sérologie bactériennes, IHU Méditerranée Infection, Marseille, et Labosud Provence Biologie, Martigues

${ }^{4}$ Aix Marseille Univ, IRD, AP-HM, MEPHI, IHU-Méditerranée Infection, Marseille, France

Mots clés: spirochètes, Lyme, Borrelia, Leptospira, Treponema pallidum

Keywords: spirochetes, Lyme, Borrelia, Leptospira, Treponema pallidum 


\section{Résumé}

Les bactéries du complexe B. burgdorferi sensu lato, qui causent la maladie de Lyme, appartiennent au phylum des spirochètes. Les difficultés diagnostiques rencontrées dans la maladie de Lyme sont en partie dues aux caractéristiques des spirochètes qui sont des bactéries dont la culture est fastidieuse, voire impossible pour certaines d'entre elles. Nous avons réalisé une revue de la littérature concernant les performances des différents tests diagnostiques dans les spirochétoses d'intérêt médical que sont la borréliose de Lyme, les borrélioses récurrentes, la syphilis et la leptospirose. Cette revue permet de dégager un certain nombre de points communs pour ces quatre infections. La PCR en temps réel a pris une place importante ces dernières années dans le diagnostic direct de ces infections. Cependant, le diagnostic direct reste difficile du fait d'un manque de sensibilité persistant et les sérologies gardent donc un rôle central dans le raisonnement diagnostique. Tous les outils diagnostiques actuels présentent des imperfections avec un risque éventuel de faux positifs et de faux négatifs en fonction du contexte clinique. Ceci doit inciter les cliniciens à une interprétation des tests diagnostiques en cas de suspicion de maladie de Lyme, Borréliose récurrente, syphilis ou leptospirose, toujours en relation avec le contexte clinique et épidémiologique dans lequel ils se trouvent. 


\begin{abstract}
Bacteria of the B. burgdorferi sensu lato complex, responsible for Lyme disease, are members of the spirochetes phylum. Diagnostic difficulties of Lyme disease are partly due to the characteristics of spirochetes as their culture is tedious or even impossible for some of them. We performed a literature review to assess the value of the various diagnostic tests of spirochetes infections of medical interest such as Lyme borreliosis, relapsing fever borreliae, syphilis, and leptospirosis. We were able to draw similarities between these four infections. Real-time PCR now plays an important role in the direct diagnosis of these infections. However, direct diagnosis remains difficult because of a persistent lack of sensitivity. Serological testing is therefore crucial in the diagnostic process. All currently available diagnostic tools are imperfect, with a potential risk of false positive and false negative results depending on the clinical context. Physicians should always take into consideration the clinical and epidemiological context when Lyme disease, relapsing fever borreliae, syphilis, and leptospirosis are suspected.
\end{abstract}




\section{Introduction}

Bacteria of the Borrelia burgdorferi sensu lato group (responsible for Lyme borreliosis) are spirochetes just like Borrelia spp. responsible for relapsing fever, Leptospira spp. responsible for leptospirosis (worldwide zoonosis transmitted through contact with urines of rodents), and Treponema spp. including the causative agents of syphilis (a sexuallytransmitted disease). Bacteria belonging to this phylum have specific characteristics, such as a helical form and motility due to pseudoflagella which help them move in viscous media [1]. Some spirochetes are commensal bacteria of humans, mainly of the oral flora, and others play a specific role in human pathology. Some Borrelia spp. transmitted by ticks or lice, are responsible for infections very different from Lyme disease, and are called relapsing fever borreliae, caused by ticks or lice. These infections all have very different clinical symptoms, and their diagnosis is based on the physical examination and physician's judgment as well as on confirmatory microbiological tests. Other specificities of bacteria belonging to this phylum are their non-Gram staining characteristics and their inability to be cultured using standard culture media. Laboratory diagnosis is therefore tedious.

Current debates are mainly sparked by patients' associations and some physicians who are questioning the reliability of Lyme borreliosis diagnostic tests. There is no such debate for other spirochetes. We assessed literature data on the value of diagnostic tests for Borrelia spp. responsible for Lyme disease and for other spirochetes of medical interest.

\section{Current quality standards and French regulations for diagnostic tests in humans}

Before analyzing scientific literature data, we should note that biomedical laboratories commercializing and performing diagnostic tests in humans have to comply with various regulations and standards in Europe and France: CE marking, inspections performed by the French Agency for the Safety of Health Products (French acronym ANSM), and COFRAC 
accreditation for laboratories performing biological tests. Manufacturers apply the $\mathrm{CE}$ marking on their tests, thus guarantying the conformity of their products with legal European requirements. The ANSM (https://ansm.sante.fr/) also performs a retrospective inspection to ensure conformity of the various biological tests marketed in France with health and safety requirements. The French accreditation committee, named COFRAC (https://www.cofrac.fr/), is the only national agency responsible for the accreditation of both public and private biology laboratories. For molecular biology techniques such as PCR detection of Borrelia, Treponema, and Leptospira, laboratories must therefore have their methods validated. Additional tests must therefore be performed to ensure the absence of laboratory contaminations for instance. Quality of the tests performed by laboratories not complying with these requirements is not ensured. It should be noted that veterinary laboratories do not have to obtain the COFRAC accreditation, and that they are not allowed to perform human biological tests since May 30, 2013.

\section{Lyme disease diagnosis}

Except in case of typical erythema migrans, a positive biological test is required to confirm Lyme borreliosis diagnosis.

\section{Direct diagnosis}

Just like other spirochetes of medical interest, Borrelia spp. responsible for Lyme borreliosis cannot be detected by standard optical microscopy nor by Gram staining. They can, however, be detected by dark-field microscopy or phase-contrast microscopy [7].

However, bacteremia observed during Lyme borreliosis, especially with European clinical presentations, is moderate, of a short duration, and only occurs at the beginning of dissemination [7]. Looking for the bacterium in blood samples when patients do not have fever is therefore useless in case of Lyme borreliosis. The few pieces of data available after 
so-called positive microscopy have actually been demonstrated to be artifacts and not Borrelia [8]. The microscopic examination does not perform well enough to be a useful tool for the biological diagnosis of Lyme borreliosis.

The in vitro culture of Borrelia from tissue biopsy (skin, synovial membrane) or from biological fluid (CSF, synovial fluid) is performed on specific liquid media: BSK-II, MKP, or BSK-H (commercialized), incubated at $32-34^{\circ} \mathrm{C}$. As the mean time to Borrelia growth is $7-20$ hours, the time to positive culture is usually more than 15 days, or even more than eight weeks [9]. Cultures should therefore be checked once a week with a dark-field microscope for at least eight weeks before being able to conclude to a negative result, because Borrelia growth does not cloud the culture medium [9]. As Borrelia are highly fragile bacteria, specimens should be inoculated directly at the patient's bedside. Considering these technical requirements, Borrelia culture from human specimens is only performed by a few specialized laboratories in Europe. Although cultures perform well with erythema migrans specimens, this method lacks sensitivity when it is used with other biological specimens (CSF, skin biopsy of acrodermatitis chronica atrophicans, and synovial fluid where only a few isolates are observed) [7]. Moreover, no strain has so far been isolated from blood specimens of patients presenting with chronic disorders several years after a tick bite; culture from blood specimens is therefore currently not recommended.

The PCR detection of Borrelia is not associated with the constraints of culture. Several PCR techniques are available and their value varies in terms of sensitivity, specificity, and detection spectrum [10]. Several PCR kits are currently commercialized, but their performance is poorly known. Direct detection of Borrelia by PCR test should thus only be performed by official and accredited specialized laboratories. However, sensitivity of the PCR test is much higher than that of culture in disseminated skin and articular presentations of the disease [11]. Nonetheless, a negative PCR test result cannot rule out the Lyme borreliosis 
diagnosis. Physicians should always keep in mind that prescribing Borrelia PCR testing in case of a negative serology is not recommended, except for patients presenting with early atypical skin lesions of erythema migrans or very early Lyme neuroborreliosis [2].

Among all direct diagnostic techniques, only PCR testing and culture - despite their limitations - can be used and have been validated for the detection of Borrelia. Microscopy techniques are indeed too often associated with artifacts and should be avoided.

\section{Indirect diagnosis}

Because of the above-mentioned limitations of direct techniques, the biological diagnosis of Lyme borreliosis is currently mainly based on serological testing. Results should always be interpreted in light of the clinical context and the incidence of the disease as they impact pre-test probability and consequently the positive and negative predictive values of the tests. Lyme borreliosis diagnosis in France is based on two-tiered serological testing in France, just like in most European countries and in the United States. This process improves the specificity of the final result [2]. The first test is usually an ELISA assay; in case of a positive or dubious result, a second confirmatory test is performed by immunoblot technique (or Western blot) to confirm the specificity of anti-Borrelia antibodies [2].

A European meta-analysis recently demonstrated that immunoblot tests used on their own were not associated with better sensitivity or specificity than ELISA tests for the diagnosis of Lyme borreliosis in Europe, whether it be for Lyme arthritis or Lyme neuroborreliosis [12]. The overall sensitivity on serum in cases of Lyme neuroborreliosis was 81\% (CI: 70-89\%) for ELISA tests and 81\% (CI: 57-96\%) for immunoblot tests, with 92\% specificity (CI: 88-89\%) for ELISA tests and 94\% (CI: 91-96\%) for immunoblot tests. For Lyme arthritis, the overall sensitivity of ELISA tests was 94\% (CI: 86-98\%) and 95\% (CI: 8498\%) for immunoblot tests, with 97\% specificity (CI: 94-98\%) for ELISA tests and 92\% (CI: 84-96\%) for immunoblot tests. This study also highlighted the lower accuracy of ELISA tests 
compared with immunoblot tests [12]. The authors of this meta-analysis also reported a slight overall improvement of these tests, although statistically non-significant, when using purified antigens and/or recombinant antigens, mainly in patients presenting with Lyme neuroborreliosis [12].

This two-tiered serological testing process improves the positive predictive value of the final result compared with a single ELISA or immunoblot test (Western blot) as they may yield up to $27 \%$ of false IgM positive results [13]. As both methods have some degree of specificity, their successive use contributes to increasing the specificity of the final result $[12]$.

However, these specificity and sensitivity values vary depending on the infection stage. No biological test is required for erythema migrans as the serological test is negative in more than $50 \%$ of cases in Europe [14]. Erythema migrans is the most frequent clinical presentation of Lyme borreliosis. It is a localized infection, associated with a low immune system response. A negative serological test result is therefore associated with a probability of wrongly ruling out the diagnosis. The biological diagnosis of Lyme neuroborreliosis is based on the joint analysis of blood and CSF [15]. CSF analysis reveals early lymphocytic cellular reaction in more than $93 \%$ of patients presenting with meningoradiculitis [16]. Lyme serology is positive in serum specimens at the acute phase of Lyme neuroborreliosis in $70-89 \%$ of cases, and sensitivity in CSF specimens at the acute phase is $>90 \%$ [16]. At the stage of Lyme arthritis or acrodermatitis chronica atrophicans, the sensitivity of Lyme serology is $95 \%$ and $98 \%$, respectively [12]. The very high negative predictive value of serology should lead to question the suggested diagnosis in case of a negative result in patients presenting with clinical signs and symptoms. One should also bear in mind that, following effective treatment, anti-Borrelia antibodies (including $\operatorname{IgM}$ ) may persist for months or even years after clinical 
cure [2]. Serological testing is therefore not useful for the follow-up of treated patients and the presence of $\operatorname{IgM}$ is not indicative of a persistent Borrelia infection.

\section{Various species of the B. burgdorferi sensu lato complex}

Various species have been defined as belonging to the B. burgdorferi sensu lato complex. Their geographical distribution is varied and they are responsible for various clinical signs and symptoms [17]. Predominant species in Europe are B. garinii and B. afzelii, while B. burgdorferi sensu stricto is most frequently observed in the United States [17].

Partial differentiation of species among the B. burgdorferi sensu lato complex by serological testing is possible because of molecular and antigen changes of surface proteins. In 1994 Wilske et al. developed an immunoblot technique based on the use of five recombinant antigens. This technique helped detect seroreactivity differences between patients infected with B. afzelii, B. garinii, or B. burgdorferi sensu stricto [18]. Two years later, Norman et al. developed an immunoblot technique using several strains of B. afzelii, B. garinii, and B. burgdorferi sensu stricto [19]. The authors revealed that European sera were more reactive to Western blot prepared with strains of $B$. garinii and B. afzelii, while sera collected from Northern American patients were more reactive to B. burgdorferi sensu stricto antigens [19]. Sera of patients presenting with neurological signs were also more reactive to B. garinii antigens and those of patients with dermatological clinical presentations were rather reactive to $B$. afzelii antigens [19]. One should note that, in this study, the interpretation of the Western blot result (positive or negative) could vary depending on the strain used for $8 \%$ of tested specimens. Other European studies using the Western blot technique reported similar results, with a preferential association of $B$. garinii and neurological disorders, B. afzelii and late cutaneous signs, and a slight predominance of B. burgdorferi sensu stricto in joint manifestations [20-22]. Consequently, as early as 1999, standardization of Western blot techniques prepared with B. garinii and B. afzelii strains was suggested in Europe [23]. To do 
so, the authors used a panel of sera from patients coming from various European regions, that had been provided by members of the European Union Concerted Action on Lyme Borreliosis (EUCALB), and compared them with those of healthy blood donors [24]. However, composition and sometimes performance differences are observed between ELISA and Western blot techniques commercialized in the various European markets [12,24]. These tests are usually prepared with a mixture of recombinant antigens from the three main pathogenic species for humans (B. burgdorferi sensu stricto, B. garinii, and B. afzelii) [6]. Including antigens from these various species mainly aims to improve the sensitivity of serological tests. However, accurate differentiation of Borrelia species can only be performed with molecular techniques; reactivity differences observed with serological tests in antigens of various species do not always result from culture or PCR, and may lead to interpretation errors.

\section{Other diagnostic tests for Lyme borreliosis}

Some tests are sometimes suggested for the diagnosis of Lyme borreliosis, although their bioclinical value has not been extensively assessed. Other tests are not validated using the methodology approved in medical biology [2]. These various techniques include lymphocyte transformation tests (LTT). LTTs currently lack validation and published studies have substantial methodological biases [3]. For instance, the diagnostic value of LTTs in Lyme neuroborreliosis is low (36\% sensitivity and 82\% specificity) [4]. Another test relies on CD57 marker detection. Little data is available and the only case-control study performed (NIH study) reported the complete lack of specificity of this test [5]. As for rapid diagnostic tests for self-testing, sensitivity and specificity data is currently very limited [6].

\section{Relapsing fever borreliae}

Relapsing fever borreliae are mainly observed in tropical and subtropical regions, and mainly in Africa. The causative agents are usually B. duttonii, B. crocidurae, B. recurrentis, 
B. persica, and B. hispanica [25]. They are transmitted by soft ticks (Argasidae) and for some of them by body lice (B. recurrentis) [25]. An emerging species, B. miyamotoi, is transmitted by hard ticks [25].

\section{Direct diagnosis}

Relapsing fever borreliae, unlike Lyme borreliosis, can lead to severe bacteremia during febrile episodes. This is why the usual diagnostic method is optical microscopy after Giemsa staining of blood smear or thick blood drop. This technique may detect concentrations of $10^{3}$ to $10^{5}$ microorganisms/mL [26-28]. Comparative studies reported that additional methods could increase the sensitivity of optical microscopy. Differential centrifugation, acridine orange, quantitative buffy coat (QBC), and fluorescence microscopy could contribute to increasing microscopy sensitivity [29-31]. Quantitative buffy coat is supposed to be 100 times more sensitive than thick blood drop for the diagnosis of relapsing fever borreliae [31]. However, such technique requires specific laboratory equipment that is often not available in endemic regions.

Molecular biology techniques such as standard PCR and quantitative PCR have been developed. Several comparative studies reported the better sensitivity of these techniques compared with usual microscopy techniques. These findings are detailed in Table 1 [32-34].

Culture may be performed but it requires expert skills, thus limiting its routine use. It is thus very rarely used with clinical samples. BSK-H culture medium is the same as the one for Borrelia spp. responsible for Lyme disease. All Borrelia species responsible for relapsing fever do not grow on this medium though. Growth is detected by dark-field microscopy.

Antigen detection in blood or other tissue specimens is being developed, but it is currently not available in clinical practice. Specific monoclonal antibodies have for instance been developed to detect B. crocidurae and B. hermsii $[35,36]$. Another innovative technique 
is the MALDI-TOF test. It has been used in the detection of Borrelia crocidurae in Ornithodoros sonrai ticks [37].

\section{Indirect diagnosis}

Specific serological tests for the causative agents of relapsing fever borreliae have been developed. They are based on the use of GlpQ antigen or BipA antigen, that are supposed to be absent from species of the burgdorferi group [7,38,39]. However, several studies reported cross reactions with bacteria of the burgdorferi sensu lato complex responsible for Lyme disease. This has for instance been observed between B. miyamotoi, B. burgdorferi, and B. hermsii in the United States [40]. The serological test is also often negative during the first fever episodes of relapsing fever and should therefore rather be used as a retrospective diagnostic tool.

\section{Syphilis: Treponema pallidum}

Syphilis is a sexually-transmitted infection caused by T. pallidum. It is a public health problem as its incidence has been on the rise in France since the years 2000 [41]. The main obstacle to diagnosis and to the study of T. pallidum is the inability to culture the bacterium in an axenic medium.

\section{Direct diagnosis}

Direct examination by dark-field microscopy of chancre or skin lesion samples is highly contributory and immediate. Performances vary according to laboratories and staff. Specific material and qualified staff are required. False positive results (commensal spirochetes, especially on the mouth or anus) and false negative results (a negative direct examination should not rule out syphilis) may be observed $[42,43]$. The sensitivity of the examination is higher at the primary and secondary phases and in early congenital syphilis (chancres, condyloma latum, mucous patches, adenopathy) [44]. 
Direct immunofluorescence for the detection of Treponema has been associated with satisfactory results at the mucous, skin lesion, or tissue levels. The sensitivity of these techniques is close to $80 \%$ [45-47]. However, these techniques have become obsolete since the commercialization of PCR tests. Various methods such as standard PCR, nested PCR, RTPCR, or quantitative PCR, have been used by targeting several genes such as bmp, tpp47, tmpA encoding for surface lipoproteins, or pol $A$ involved in genome replication [48]. Recent studies reported no performance differences between PCR testing targeting the gene encoding for the membrane protein of $47 \mathrm{Kd}$ and that targeting the gene encoding for the "pol A" polymerase DNA gene [49]. Sensitivity is approximately $80 \%$ and specificity $95 \%$; and $95 \%$ and $89 \%$ negative and positive predictive values have been reported, respectively $[49,50]$. Just like for other spirochetes of medical interest, the values of PCR tests depend on biological samples tested and infection stages. For illustrative purposes, patients presenting with secondary syphilis or patients co-infected with HIV with a low level of CD4 lymphocytes, have higher rates of spirochetemia than patients presenting with primary syphilis or patients at the early latency phase. Blood PCR testing is therefore associated with better sensitivity in these patients [51]. PCR techniques have been assessed in the detection of T. pallidum DNA in swabs of chancre, cutaneous biopsy of secondary syphilis, bones, various biological fluids such as serum, CSF, urines, placenta, gastric lesions [52-60]. PCR testing is thus recommended as a diagnostic tool for primary and secondary syphilis. However, because of an insufficient sensitivity, its negativity should not rule out the diagnosis and an indirect diagnostic test should also be performed.

\section{Indirect diagnosis}

No serological test for syphilis is able to differentiate venereal syphilis caused by Treponema pallidum pallidum, and non-venereal Treponema infections caused by T. pallidum subsp. endemicum (responsible for Bejel), T. pallidum subsp. pertenue (responsible for 
Yaws), and T. pallidum carateum (responsible for Pinta). Two types of tests are available: nontreponemal tests (NTT) and treponemal tests (TT).

\section{Nontreponemal tests (NTT)}

These tests are based on the use of a complex antigen, made of cardiolipin, lecithin, and cholesterol [44]. The venereal disease research laboratory test (VDRL) and rapid plasma reagin test (RPR) are the most frequently used. The RPR test is made of charcoal particles coated with a mixture of lipid antigens [44]. Consequently, anti-lipid antibodies detected by these tests are not only produced during Treponema infection, but also in case of any other disease responsible for tissue lesions. As many cross reactions are observed, these tests alone cannot confirm the syphilis diagnosis. In case of infection, these tests are positive 10 to 15 days after primary chancre, i.e. six weeks following contact. In the absence of treatment, the highest level is reached between one and two years and remains positive at lower levels during late phases of syphilis [44]. Complete seronegativation during tertiary syphilis is extremely rare. NTT titers are also correlated with the infection activity, and are thus used to control treatment effectiveness. Sensitivity values of these tests thus vary depending on the disease stage [44]. During the primary phase (at the chancre stage), sensitivity of the RPR and VDRL tests is low, respectively $86 \%$ and $78 \%$ [44,61]. Sensitivity is $100 \%$ for both NTTs at the secondary phase, and $71 \%$ for VDRL and $71 \%$ for RPR at the late phase [44,61]. Specificity is $98 \%$ at all infection stages [44]. The risk of prozone reaction triggering false negative results is another problem observed with NTTs. This reaction is observed in up to $2 \%$ of patients presenting with secondary syphilis, in serum specimens with a high number of antibodies. The normal antigen-antibody reaction is therefore inhibited [44]. Weakly positive results, dubious results, or even negative results are in that case observed. It is thus recommended to dilute samples to first obtain increased titers and then a progressive decrease [44]. 
These tests are also associated with a risk of false positive results, mainly because of the type of lipid antigens used: they yield a positive result in cases such as acute hepatitis, infectious mononucleosis, pneumonia, chickenpox, measles, pregnancy, or malaria [44]. Chronic diseases such as autoimmune diseases (mainly lupus), cancers, leprosy, or intravenous drug use may lead to positive results with NTTs.

\section{Treponemal tests (TT)}

TTs are based on the detection of antibodies targeted against antigens that are part of Treponema. All TTs use T. pallidum as antigen. Their specificity is better than that of NTTs, but they always yield positive results after treatment. Active syphilis thus cannot be distinguished from a serological scar [44]. These tests are T. pallidum hemagglutination assay (TPHA), T. pallidum particle agglutination assay (TPPA), and fluorescent treponemal antibody absorbed test (FTA) [62]. More recent immunoenzyme techniques are available, such as the ELISA assay or CMIA (chemiluminescent microparticles immunoassay). Agglutination and fluorescence tests are usually manually performed (TPHA, TPPA, FTA), whereas immunoenzyme tests are automated and multiplex tests have even been recently developed [62]. Sensitivity and specificity values of the various TTs are reported in Table 2. Automated techniques (ELISA, CMIA BIOPLEX) are usually more sensitive and specific than manually performed tests (FTA, TPPA, and TPHA) [62,63].

Western blot tests may also be used to confirm results, with up to $99.9 \%$ sensitivity and specificity [41,64-66]. These tests are able to detect antibodies targeted against antigen proteins such as $\mathrm{TpN} 15, \mathrm{TpN} 17, \mathrm{TpN} 45$, or TmpA. They are considered positive with at least two strips of IgG or one strip of IgM. They are particularly useful when other serological tests yield discordant results, or for congenital syphilis diagnosis because pregnancy is a cause of false positive results with NTTs and possibly with the more usual TTs [41]. Looking for IgM 
by Western blot technique in children enables the distinction between passive transmission of IgG mother antibodies and active synthesis of IgM by the newborn.

\section{Strategy for serological diagnosis}

The French National Authority for Health (French acronym HAS) suggested a new screening strategy in 2015. This strategy is based on two-tiered serological testing: an automated TT (ELISA, EIA, or CMIA) to detect IgG and IgM [67], followed by confirmatory quantitative NTT if the first test result is positive. A recent study performed by the centers for disease control and prevention (CDC) evaluated five laboratories using this strategy in the United States. The authors revealed that up to $56 \%$ of patients with a positive automated TT result had a negative NTT result (RPR) and that $36 \%$ of them also had a negative TPPA or FTA result [68]. This proportion of false positive results was higher among populations known to be associated with a low prevalence of syphilis [68]. Such evaluation has so far not been conducted in France, where the use of this strategy is more recent.

\section{Leptospirosis}

Leptospirosis is a zoonosis caused by pathogenic spirochetes of the Leptospira genus. It is transmitted to humans by direct or indirect contact (through contaminated water mainly) with the urine of infected animals [69]. The clinical presentation of the disease is divided into two phases: a febrile, bacteremia phase of variable duration and an immune phase characterized by antibody production and excretion of Leptospira in urines, that may be associated with fever [69]. Most symptoms associated with disease severity (jaundice, lung involvement, renal involvement, meningitis) are observed during the immune phase. Just like other spirochetes mentioned in the present article, the value and interpretation of biological tests depend on the infection stage.

\section{Direct diagnosis}


The detection of Leptospira requires a dark-field microscope or a phase-contrast microscope [69]. Leptospira are spiral-shaped bacteria (6 to $12 \mu \mathrm{m}$ long and $0.1 \mu \mathrm{m}$ in diameter), with mobile hooked ends [69]. The direct examination with a dark-field microscope is weakly sensitive and poorly specific, with a detection threshold of $10^{4}$ Leptospira/mL [69]. This method only yields positive results during the bacteremia phase of the infection, but has to be performed by a laboratory technician. The risk of false positive results is also high due to the presence of fibrin filaments or protein fragments which are moved by Brownian motion process [69]. Leptospira may be cultured from biological fluids such as blood, CSF, or urine. Blood samples should be collected in heparin tubes during the febrile period and inoculated on the specific EMJH culture medium [70]. Samples should be incubated in a dark room at $28-30^{\circ} \mathrm{C}$ for at least eight weeks, and analyzed weekly with a dark-field microscope [69]. CSF may be cultured in case of meningitis signs and symptoms, with the same modalities. Urines are alkalized and inoculated within four hours (the acidity of urines lyses Leptospira) with serial dilutions at $1 / 10$ and $1 / 100$ [69]. Isolated strains are identified by agglutination tests on specific antiserum. Genotypic identification techniques are also more frequently used $[71,72]$.

PCR is currently the most frequently used direct diagnostic method and allows for the early diagnosis of the infection before antibody detection. $\sec Y$ (flagellin), $r r s, f l a B$, and $r r l$ genes and the LA 3521 locus are used in the various methods currently available [70]. PCR detection has been used on blood, urine, CSF, and aqueous humor samples with different performances [70]. The sensitivity and specificity values on blood samples are unfortunately highly variable and are even lower with late PCR testing than early PCR testing at the start of the infection (from $9 \%$ to $73 \%$ and $52 \%$ to $100 \%$, respectively) [73, 74]. The detection threshold is set at 10 to 50 Leptospira/mL of blood. PCR testing on urine samples is associated with better performance and specificity and sensitivity values of $100 \%$, although 
based on only one study [70,74]. Quantitative PCR has now replaced standard PCR, with increasing sensitivity and specificity values (96\% and $100 \%$, respectively) [75].

\section{Indirect diagnosis}

The historical reference serological technique is the microscopic agglutination test (MAT) [69]. Developed in 1918 by Martin and Pettit, this method relies on serum incubation with Leptospira antigen suspension of various serovars and on looking for agglutination with a dark-field microscope. Serological titer can thus be determined, corresponding to the highest dilution at which a 50\% agglutination is observed [69]. This method requires particular expertise to maintain representative strains of each serovar in culture. It is thus only performed by reference centers. It also helps identify the causative serogroup, which is useful for epidemiological purposes. Although considered a reference method, sensitivity values are not optimal at all stages of the infection (82\% at Week 2 of the infection, 96\% after Week 4) [69]. Significant titers are 100 in endemic regions and 400 in non-endemic regions [76].

Various ELISA serological tests enabling the detection of anti-Leptospira IgM, have been commercialized over the past few years. These tests are more easily used and are better standardized. The value of these commercialized tests is highly variable depending on studies (sensitivity ranging from $4 \%$ to $97 \%$ ), mainly because some studies performed the serological test during the first week of the infection. Nonetheless, studies performing the serological test after Day 7 reported sensitivity and specificity values between $75 \%$ and $100 \%$ and $78 \%$ and 97\%, respectively [77-81]. These tests are therefore currently recommended as first-line strategies during the immune phase of the infection, with secondary confirmation by MAT [81].

Another type of technique based on unit tests with visual interpretation on strips has been developed [81]. It is based on the same principle as the ELISA assay, but the antigen is 
fixed on a strip. The added value of this test relies on its ease of use, although limited by its expensive price. This method has never been fully assessed in metropolitan France, but its sensitivity is believed to be lower than the usual ELISA techniques. Its use is therefore not currently recommended, except in isolated regions of French overseas territories [81]. The slide microagglutination test with a thermoresistant antigen has long been used as a screening technique before MAT confirmation. Total antibodies can thus be detected during the second week of the infection [81]. Tests used in France are associated with sensitivity values ranging from $45 \%$ to $63 \%$ and specificity values from $84 \%$ to $88 \%$. The HAS thus decided in 2011 to no longer use this test as part of the diagnostic strategy of leptospirosis [81].

\section{Diagnostic scores}

Considering the limitations of the various diagnostic tests of leptospirosis and their poor availability in resource-limited countries where the infection prevalence is high, the WHO developed specific diagnostic criteria in 1982: Faine criteria (Table 3) [82]. These criteria are divided into a clinical category, an epidemiological category, and a biological diagnosis category (Table 3). The latter category was modified in 2012 to include more recent diagnostic methods than MAT, as well as the risk factor of "rainfall before symptom onset" [83]. The leptospirosis diagnosis is highly suspected when the score is $>20$, with high probability when $>24$ (Table 3 ) [84]. This modified score has newly been evaluated in a recent study conducted in Sri Lanka, and sensitivity and specificity values of $95 \%$ and $56 \%$, respectively, have been reported [85]. Several predictive diagnostic scores have since been developed. A Sri Lankan team thus suggested using a score based on a derivation cohort of 450 patients suspected of having leptospirosis and on a validation cohort of 142 patients with a confirmed diagnosis of leptospirosis [86]. This score includes five items, each with values ranging from 4 to 6 : bilirubinemia $>30 \mathrm{mmol} / \mathrm{L},>80 \%$ of neutrophils, exposure to 
contaminated water or soil, creatininemia $>150 \mu \mathrm{mol} / \mathrm{L}$, platelet count $<85 \mathrm{Giga} / \mathrm{L}$ [86]. A threshold score of 14 was associated with an $80 \%$ sensitivity, a $62 \%$ specificity, a positive predictive value of $54 \%$, and a negative predictive value of $84 \%$ [86].

\section{Conclusion}

This literature review on biological diagnostic tests for spirochetes responsible for infections in humans, highlighted several similarities between these bacteria. For all studied bacteria, the direct diagnostic methods are not optimal. Dark-field microscopy has to be performed by a laboratory technician. Culture is always tedious or even impossible on an axenic medium such as for syphilis. The commercialization of real-time PCR techniques represented major progress for the four infections studied in the present article, as they are more sensitive than culture and as they can be more easily standardized. However, the likelihood of a positive PCR result depends on the infection stage (bacteremia stage for Leptospira or relapsing fever borreliae) and on the type of sample collected (erythema migrans biopsy for Lyme disease, genital chancre for syphilis).

As for indirect diagnostic methods, false negative results are mainly observed at the early stage of the four infections when no or not enough specific antibodies are produced. Serological tests are also all associated with cross reactions, with a risk of false positive results, and consequently with a risk of excessive diagnoses and treatments.

This risk of false positive results is known and can be measured thanks to Bayes' theorem, developed in the $18^{\text {th }}$ century. False positive results are indeed an inherent difficulty to all medical diagnostic tests as no test is perfect. This risk is higher if the probability of having the disease in the studied population is low. Thus, to reduce the risk of false positive results with a given test, one should select a population associated with an "a priori" higher disease prevalence than in the general population. Several strategies have been developed. 
The first strategy consists in performing the test in a population that has been selected for its risk factors for the infection. For instance, when performing an HIV serological test in a group of intravenous drug users sharing syringes, the infection prevalence will be much higher than if we were testing random people among the general population. Such strategy thus leads to decreasing the number of false positive results. Diagnostic scores such as those developed for leptospirosis are also based on that same principle. Another strategy consists in performing two tests: a screening test, more sensitive than specific, which will yield many false positive results although enabling the selection of a population subgroup where the disease prevalence is a priori higher. The first test should then be confirmed with a more specific test to improve the overall relevance of the test result. For Lyme borreliosis, this strategy is applied with a sensitive but weakly specific ELISA serological test - and thus associated with false positive results - followed by a more specific confirmatory Western blot test.

\section{Disclosure of interests}

Didier Raoult and Oleg Mediannikov applied for a patent for a monoclonal antibody enabling the detection of Borrelia crocidurae. 


\section{References}

1. Wolgemuth CW, Charon NW, Goldstein SF, Goldstein RE. The flagellar cytoskeleton of the spirochetes. J Mol Microbiol Biotechnol 2006; 11:221-227.

2. Dessau RB, van Dam AP, Fingerle V, et al. To test or not to test? Laboratory support for the diagnosis of Lyme borreliosis: a position paper of ESGBOR, the ESCMID study group for Lyme borreliosis. Clin Microbiol Infect Off Publ Eur Soc Clin Microbiol Infect Dis 2018; 24:118-124.

3. Dessau RB, Fingerle V, Gray J, et al. The lymphocyte transformation test for the diagnosis of Lyme borreliosis has currently not been shown to be clinically useful. Clin Microbiol Infect Off Publ Eur Soc Clin Microbiol Infect Dis 2014; 20:O786-787.

4. Nordberg M, Forsberg P, Nyman D, et al. Can ELISPOT Be Applied to A Clinical Setting as A Diagnostic Utility for Neuroborreliosis? Cells 2012; 1:153-167.

5. Marques A, Brown MR, Fleisher TA. Natural killer cell counts are not different between patients with post-Lyme disease syndrome and controls. Clin Vaccine Immunol CVI 2009; 16:1249-1250.

6. Réactifs de sérologie de la borréliose de lyme - ANSM : Agence nationale de sécurité du médicament et des produits de santé. Available at: https://ansm.sante.fr/Activites/Surveillance-du-marche-des-dispositifs-medicaux-etdispositifs-medicaux-de-diagnostic-in-vitro-DM-DMDIV/Dispositifs-medicaux-dediagnostic-in-vitro-Operations-d-evaluations-et-de-controle-du-marche/Dispositifs-medicauxde-diagnostic-in-vitro-Operations-d-evaluations-et-de-controle-du-marche/Reactifs-deserologie-de-la-borreliose-de-lyme. Accessed 26 August 2018.

7. Cutler SJ, Rudenko N, Golovchenko M, et al. Diagnosing Borreliosis. Vector Borne Zoonotic Dis Larchmt N 2017; 17:2-11.

8. Aase A, Hajdusek $O$, Øines $\varnothing$, et al. Validate or falsify: Lessons learned from a microscopy method claimed to be useful for detecting Borrelia and Babesia organisms in human blood. Infect Dis Lond Engl 2016; 48:411-419.

9. Schramm F, Grillon A, Martino SD, Jaulhac B. La borréliose de Lyme. Rev Francoph Lab 2013; 2013:35-49.

10. Faller M, Hiergeist A, Reischl U, et al. EU-wide external quality assessement study on the sensitivity and specificity of different amplication protocol for détection of Borrelia burgdorferi sensu lato. 14th Int Conf Lyme Borreliosis Tick-Borne Dis 2015;

11. Aguero-Rosenfeld ME, Wang G, Schwartz I, Wormser GP. Diagnosis of lyme borreliosis. Clin Microbiol Rev 2005; 18:484-509.

12. Leeflang MMG, Ang CW, Berkhout J, et al. The diagnostic accuracy of serological tests for Lyme borreliosis in Europe: a systematic review and meta-analysis. BMC Infect Dis 2016; $16: 140$.

13. Seriburi V, Ndukwe N, Chang Z, Cox ME, Wormser GP. High frequency of false positive IgM immunoblots for Borrelia burgdorferi in clinical practice. Clin Microbiol Infect Off Publ Eur Soc Clin Microbiol Infect Dis 2012; 18:1236-1240.

14. Stanek G, Fingerle V, Hunfeld K-P, et al. Lyme borreliosis: clinical case definitions for diagnosis and management in Europe. Clin Microbiol Infect Off Publ Eur Soc Clin Microbiol Infect Dis 2011; 17:69-79.

15. Blanc F, Jaulhac B, Fleury M, et al. Relevance of the antibody index to diagnose Lyme neuroborreliosis among seropositive patients. Neurology 2007; 69:953-958.

16. Ogrinc K, Lusa L, Lotrič-Furlan S, et al. Course and Outcome of Early European Lyme Neuroborreliosis (Bannwarth Syndrome): Clinical and Laboratory Findings. Clin Infect Dis Off Publ Infect Dis Soc Am 2016; 63:346-353.

17. Stanek G, Reiter M. The expanding Lyme Borrelia complex--clinical significance of genomic species? Clin Microbiol Infect Off Publ Eur Soc Clin Microbiol Infect Dis 2011; 
17:487-493.

18. Wilske B, Fingerle V, Preac-Mursic V, et al. Immunoblot using recombinant antigens derived from different genospecies of Borrelia burgdorferi sensu lato. Med Microbiol Immunol (Berl) 1994; 183:43-59.

19. Norman GL, Antig JM, Bigaignon G, Hogrefe WR. Serodiagnosis of Lyme borreliosis by Borrelia burgdorferi sensu stricto, B. garinii, and B. afzelii western blots (immunoblots). J Clin Microbiol 1996; 34:1732-1738.

20. Ryffel K, Péter O, Rutti B, Suard A, Dayer E. Scored antibody reactivity determined by immunoblotting shows an association between clinical manifestations and presence of Borrelia burgdorferi sensu stricto, B. garinii, B. afzelii, and B. Valaisiana in humans. J Clin Microbiol 1999; 37:4086-4092.

21. Péter O, Bretz A-G, Postic D, Dayer E. Association of distinct species of Borrelia burgdorferi sensu lato with neuroborreliosis in Switzerland. Clin Microbiol Infect Off Publ Eur Soc Clin Microbiol Infect Dis 1997; 3:423-431.

22. Grygorczuk S, Péter O, Kondrusik M, et al. Assessment of the frequency of different Borrelia burgdorferi sensu lato species in patients with Lyme borreliosis from north-east Poland by studying preferential serologic response and DNA isolates. Ann Agric Environ Med AAEM 2013; 20:21-29.

23. Hauser U, Lehnert G, Wilske B. Validity of interpretation criteria for standardized Western blots (immunoblots) for serodiagnosis of Lyme borreliosis based on sera collected throughout Europe. J Clin Microbiol 1999; 37:2241-2247.

24. Dickeson DJ, Chen SC-A, Sintchenko VG. Concordance of four commercial enzyme immunoassay and three immunoblot formats for the detection of Lyme borreliosis antibodies in human serum: the two-tier approach remains. Pathology (Phila) 2016; 48:251-256.

25. Talagrand-Reboul E, Boyer PH, Bergström S, Vial L, Boulanger N. Relapsing Fevers: Neglected Tick-Borne Diseases. Front Cell Infect Microbiol 2018; 8:98.

26. Parola P, Raoult D. Ticks and tickborne bacterial diseases in humans: an emerging infectious threat. Clin Infect Dis Off Publ Infect Dis Soc Am 2001; 32:897-928.

27. Trape JF, Duplantier JM, Bouganali H, et al. Tick-borne borreliosis in west Africa. Lancet Lond Engl 1991; 337:473-475.

28. Vial L, Diatta G, Tall A, et al. Incidence of tick-borne relapsing fever in west Africa: longitudinal study. Lancet Lond Engl 2006; 368:37-43.

29. Larsson C, Bergström S. A novel and simple method for laboratory diagnosis of relapsing Fever borreliosis. Open Microbiol J 2008; 2:10-12.

30. Cobey FC, Goldbarg SH, Levine RA, Patton CL. Short report: Detection of borrelia (relapsing fever) in rural Ethiopia by means of the quantitative buffy coat technique. Am $\mathrm{J}$ Trop Med Hyg 2001; 65:164-165.

31. van Dam AP, van Gool T, Wetsteyn JC, Dankert J. Tick-borne relapsing fever imported from West Africa: diagnosis by quantitative buffy coat analysis and in vitro culture of Borrelia crocidurae. J Clin Microbiol 1999; 37:2027-2030.

32. Elbir H, Henry M, Diatta G, et al. Multiplex Real-Time PCR Diagnostic of Relapsing Fevers in Africa. PLoS Negl Trop Dis 2013; 7. Available at: http://www.ncbi.nlm.nih.gov/pmc/articles/PMC3561136/. Accessed 25 March 2015.

33. Karan L, Makenov M, Kolyasnikova N, Stukolova O, Toporkova M, Olenkova O. Dynamics of Spirochetemia and Early PCR Detection of Borrelia miyamotoi. Emerg Infect Dis 2018; 24:860-867.

34. Antinori S, Tonello C, Edouard S, et al. Diagnosis of Louse-Borne Relapsing Fever despite Negative Microscopy in Two Asylum Seekers from Eastern Africa. Am J Trop Med Hyg 2017; 97:1669-1672.

35. Fotso Fotso A, Mediannikov O, Nappez C, Azza S, Raoult D, Drancourt M. 
Monoclonal Antibodies for the Diagnosis of Borrelia crocidurae. Am J Trop Med Hyg 2016; 94:61-67.

36. Schwan TG, Gage KL, Karstens RH, Schrumpf ME, Hayes SF, Barbour AG. Identification of the tick-borne relapsing fever spirochete Borrelia hermsii by using a speciesspecific monoclonal antibody. J Clin Microbiol 1992; 30:790-795.

37. Fotso Fotso A, Mediannikov O, Diatta G, et al. MALDI-TOF mass spectrometry detection of pathogens in vectors: the Borrelia crocidurae/Ornithodoros sonrai paradigm. PLoS Negl Trop Dis 2014; 8:e2984.

38. Fritz CL, Payne JR, Schwan TG. Serologic evidence for Borrelia hermsii infection in rodents on federally owned recreational areas in California. Vector Borne Zoonotic Dis Larchmt N 2013; 13:376-381.

39. Lopez JE, Schrumpf ME, Nagarajan V, Raffel SJ, McCoy BN, Schwan TG. A novel surface antigen of relapsing fever spirochetes can discriminate between relapsing fever and Lyme borreliosis. Clin Vaccine Immunol CVI 2010; 17:564-571.

40. Krause PJ, Carroll M, Fedorova N, et al. Human Borrelia miyamotoi infection in California: Serodiagnosis is complicated by multiple endemic Borrelia species. PloS One 2018; 13:e0191725.

41. Morshed MG, Singh AE. Recent trends in the serologic diagnosis of syphilis. Clin Vaccine Immunol CVI 2015; 22:137-147.

42. Wheeler HL, Agarwal S, Goh BT. Dark ground microscopy and treponemal serological tests in the diagnosis of early syphilis. Sex Transm Infect 2004; 80:411-414.

43. Organization WH. Guidelines for the Management of Sexually Transmitted Infections. World Health Organization, 2003.

44. Larsen SA, Steiner BM, Rudolph AH. Laboratory diagnosis and interpretation of tests for syphilis. Clin Microbiol Rev 1995; 8:1-21.

45. Daniels KC, Ferneyhough HS. Specific direct fluorescent antibody detection of Treponema pallidum. Health Lab Sci 1977; 14:164-171.

46. Romanowski B, Forsey E, Prasad E, Lukehart S, Tam M, Hook EW. Detection of Treponema pallidum by a fluorescent monoclonal antibody test. Sex Transm Dis 1987; 14:156-159.

47. Ito F, Hunter EF, George RW, Pope V, Larsen SA. Specific immunofluorescent staining of pathogenic treponemes with a monoclonal antibody. J Clin Microbiol 1992; 30:831-838.

48. Grange PA, Gressier L, Dion PL, et al. Evaluation of a PCR test for detection of treponema pallidum in swabs and blood. J Clin Microbiol 2012; 50:546-552.

49. Gayet-Ageron A, Combescure C, Lautenschlager S, Ninet B, Perneger TV. Comparison of Diagnostic Accuracy of PCR Targeting the 47-Kilodalton Protein Membrane Gene of Treponema pallidum and PCR Targeting the DNA Polymerase I Gene: Systematic Review and Meta-analysis. J Clin Microbiol 2015; 53:3522-3529.

50. Heymans R, van der Helm JJ, de Vries HJC, Fennema HSA, Coutinho RA, Bruisten SM. Clinical value of Treponema pallidum real-time PCR for diagnosis of syphilis. J Clin Microbiol 2010; 48:497-502.

51. Wu B-R, Tsai M-S, Yang C-J, et al. Spirochetemia due to Treponema pallidum using polymerase-chain-reaction assays in patients with early syphilis: prevalence, associated factors and treatment response. Clin Microbiol Infect Off Publ Eur Soc Clin Microbiol Infect Dis 2014; 20:0524-527.

52. Sánchez PJ, Wendel GD, Grimprel E, et al. Evaluation of molecular methodologies and rabbit infectivity testing for the diagnosis of congenital syphilis and neonatal central nervous system invasion by Treponema pallidum. J Infect Dis 1993; 167:148-157.

53. Buffet M, Grange PA, Gerhardt P, et al. Diagnosing Treponema pallidum in secondary 
syphilis by PCR and immunohistochemistry. J Invest Dermatol 2007; 127:2345-2350.

54. Burstain JM, Grimprel E, Lukehart SA, Norgard MV, Radolf JD. Sensitive detection of Treponema pallidum by using the polymerase chain reaction. J Clin Microbiol 1991; 29:62-69.

55. Centurion-Lara A, Castro C, Shaffer JM, Van Voorhis WC, Marra CM, Lukehart SA. Detection of Treponema pallidum by a sensitive reverse transcriptase PCR. J Clin Microbiol 1997; 35:1348-1352.

56. Gayet-Ageron A, Laurent F, Schrenzel J, et al. Performance of the 47-kilodalton membrane protein versus DNA polymerase I genes for detection of Treponema pallidum by PCR in ulcers. J Clin Microbiol 2015; 53:976-980.

57. Gordon SM, Eaton ME, George R, et al. The response of symptomatic neurosyphilis to high-dose intravenous penicillin $G$ in patients with human immunodeficiency virus infection. N Engl J Med 1994; 331:1469-1473.

58. Hay PE, Clarke JR, Strugnell RA, Taylor-Robinson D, Goldmeier D. Use of the polymerase chain reaction to detect DNA sequences specific to pathogenic treponemes in cerebrospinal fluid. FEMS Microbiol Lett 1990; 56:233-238.

59. Kouznetsov AV, Weisenseel P, Trommler P, Multhaup S, Prinz JC. Detection of the 47-kilodalton membrane immunogen gene of Treponema pallidum in various tissue sources of patients with syphilis. Diagn Microbiol Infect Dis 2005; 51:143-145.

60. Wicher K, Noordhoek GT, Abbruscato F, Wicher V. Detection of Treponema pallidum in early syphilis by DNA amplification. J Clin Microbiol 1992; 30:497-500.

61. Cantor AG, Pappas M, Daeges M, Nelson HD. Screening for Syphilis: Updated Evidence Report and Systematic Review for the US Preventive Services Task Force. JAMA 2016; 315:2328-2337.

62. Marangoni A, Nardini P, Foschi C, et al. Evaluation of the BioPlex 2200 syphilis system as a first-line method of reverse-sequence screening for syphilis diagnosis. Clin Vaccine Immunol CVI 2013; 20:1084-1088.

63. Fakile YF, Jost H, Hoover KW, et al. Correlation of Treponemal Immunoassay Signal Strength Values with Reactivity of Confirmatory Treponemal Testing. J Clin Microbiol 2018; 56.

64. Janier M, Hegyi V, Dupin N, et al. 2014 European guideline on the management of syphilis. J Eur Acad Dermatol Venereol JEADV 2014; 28:1581-1593.

65. Novikov AI, Dolgikh TI, Novikov IA. [Western blot as a confirming test in the laboratory diagnosis of syphilis]. Klin Lab Diagn 2011; :44-45.

66. Ebel A, Vanneste L, Cardinaels M, et al. Validation of the INNO-LIA syphilis kit as a confirmatory assay for Treponema pallidum antibodies. J Clin Microbiol 2000; 38:215-219.

67. HAS 2015 syphilis - Recherche Google. Available at: https://www.google.com/search?q=HAS+2015+syphilis\&ie=utf-8\&oe=utf-8\&client=firefoxb. Accessed 6 May 2018.

68. Centers for Disease Control and Prevention (CDC). Discordant results from reverse sequence syphilis screening--five laboratories, United States, 2006-2010. MMWR Morb Mortal Wkly Rep 2011; 60:133-137.

69. Levett PN. Leptospirosis. Clin Microbiol Rev 2001; 14:296-326.

70. Toyokawa T, Ohnishi M, Koizumi N. Diagnosis of acute leptospirosis. Expert Rev Anti Infect Ther 2011; 9:111-121.

71. Ahmed A, Ferreira AS, Hartskeerl RA. Multilocus sequence typing (MLST): markers for the traceability of pathogenic Leptospira strains. Methods Mol Biol Clifton NJ 2015; 1247:349-359.

72. Boonsilp S, Thaipadungpanit J, Amornchai P, et al. A single multilocus sequence typing (MLST) scheme for seven pathogenic Leptospira species. PLoS Negl Trop Dis 2013; 
7:e1954.

73. Smythe LD, Smith IL, Smith GA, et al. A quantitative PCR (TaqMan) assay for pathogenic Leptospira spp. BMC Infect Dis 2002; 2:13.

74. Slack AT, Symonds ML, Dohnt MF, Smythe LD. Identification of pathogenic Leptospira species by conventional or real-time PCR and sequencing of the DNA gyrase subunit B encoding gene. BMC Microbiol 2006; 6:95.

75. Espy MJ, Uhl JR, Sloan LM, et al. Real-time PCR in clinical microbiology: applications for routine laboratory testing. Clin Microbiol Rev 2006; 19:165-256.

76. Wuthiekanun V, Sirisukkarn N, Daengsupa P, et al. Clinical diagnosis and geographic distribution of leptospirosis, Thailand. Emerg Infect Dis 2007; 13:124-126.

77. Yersin C, Bovet P, Smits HL, Perolat P. Field evaluation of a one-step dipstick assay for the diagnosis of human leptospirosis in the Seychelles. Trop Med Int Health TM IH 1999; $4: 38-45$.

78. Bajani MD, Ashford DA, Bragg SL, et al. Evaluation of four commercially available rapid serologic tests for diagnosis of leptospirosis. J Clin Microbiol 2003; 41:803-809.

79. Vijayachari P, Sugunan AP, Sehgal SC. Evaluation of Lepto Dri Dot as a rapid test for the diagnosis of leptospirosis. Epidemiol Infect 2002; 129:617-621.

80. Levett PN, Branch SL. Evaluation of two enzyme-linked immunosorbent assay methods for detection of immunoglobulin $\mathrm{M}$ antibodies in acute leptospirosis. Am $\mathrm{J}$ Trop Med Hyg 2002; 66:745-748.

81. Haute Autorité de Santé - Diagnostic biologique de la leptospirose. Available at: https://www.has-sante.fr/portail/jcms/c_1084168/fr/diagnostic-biologique-de-la-leptospirose. Accessed 7 May 2018.

82. Faine S, Organization WH. Guidelines for the control of leptospirosis. 1982; Available at: http://apps.who.int/iris/handle/10665/37219. Accessed 5 July 2018.

83. Shivakumar S, Shareek PS. Diagnosis of leptospirosis utilizing modified Faine's criteria. J Assoc Physicians India 2004; 52:678-679.

84. Doudier B, Garcia S, Quennee V, Jarno P, Brouqui P. Prognostic factors associated with severe leptospirosis. Clin Microbiol Infect Off Publ Eur Soc Clin Microbiol Infect Dis 2006; 12:299-300.

85. Bandara K, Weerasekera MM, Gunasekara C, Ranasinghe N, Marasinghe C, Fernando N. Utility of modified Faine's criteria in diagnosis of leptospirosis. BMC Infect Dis 2016; 16. Available at: https://www.ncbi.nlm.nih.gov/pmc/articles/PMC4995749/. Accessed 5 July 2018.

86. Rajapakse S, Weeratunga P, Niloofa R, et al. A Diagnostic Scoring Model for Leptospirosis in Resource Limited Settings. PLoS Negl Trop Dis 2016; 10:e0004513.

87. Jiang J, Temenak JJ, Richards AL. Real-time PCR duplex assay for Rickettsia prowazekii and Borrelia recurrentis. Ann N Y Acad Sci 2003; 990:302-310.

88. Diatta G, Trape JF, Legros F, Rogier C, Duplantier JM. A comparative study of three methods of detection of Borrelia crocidurae in wild rodents in Senegal. Trans R Soc Trop Med Hyg 1994; 88:423-424. 
Tableau 1. Sensibilité des différentes méthodes de diagnostic direct des borrélioses récurrentes

Table 1. Sensitivity of the various direct diagnostic methods for relapsing fever borreliae

\begin{tabular}{|l|l|l|}
\hline Method & Characteristics & Reference \\
Bultiplex qPCR for & Cut-off $36 \mathrm{Ct}=100$ copies & {$[32]$} \\
B.duttoni/recurrentis, and & of plasmids $5 \mu 1$ & \\
B. hispanica & & \\
\hline B. recurrentis qPCR & 3 copies 40.94 & \\
\hline Thick blood drop & 32 copies 36.92 & {$[87]$} \\
\hline Quantitative buffy coat & $10^{4}$-10 & {$[31]$} \\
\hline Inoculation to mice & Borrelia vivantes in culture & {$[88]$} \\
\hline
\end{tabular}


Tableau 2. Résumé des valeurs de sensibilité et spécificité des différents tests tréponémiques

Table 2. Summary of sensitivity and specificity values of the various treponemal tests

\begin{tabular}{|l|l|l|l|l|l|}
\hline & Primary phase & Secondary phase & Latency phase & Late phase & Specificity \\
\hline FTA-ABS & $84(70-100)$ & 100 & 100 & 96 & $97(94-100)$ \\
\hline TPHA & $76(69-90)$ & 100 & $97(97-100)$ & 94 & $99(98-100)$ \\
\hline TPPA & & $84-100$ & 99.5 \\
\hline CMIA & \multicolumn{3}{|c|}{99.38} & 99 \\
\hline ELISA & \multicolumn{3}{|c|}{98.12} & 99 \\
\hline
\end{tabular}


Tableau 3. Score diagnostique de la leptospirose

Table 3. Diagnostic score for leptospirosis

\begin{tabular}{|c|c|}
\hline Part A: clinical data & Score \\
\hline Headaches & 2 \\
\hline Fever & 2 \\
\hline Temperature $>39^{\circ} \mathrm{C}$ & 2 \\
\hline Bilateral conjunctivitis & 4 \\
\hline Meningitis & 4 \\
\hline Muscle pain, mainly on the calves & 4 \\
\hline Conjunctivitis + meningism + muscle & \\
\hline pain & 10 \\
\hline Clinical jaundice & 1 \\
\hline Albuminuria & 2 \\
\hline Part B: epidemiological factors & Score \\
\hline Rainfall & 5 \\
\hline Contact with a polluted environment & 4 \\
\hline Contact with an animal & 1 \\
\hline Part C: bacteriology & \\
\hline Leptospira isolated from culture & Confirmed diagnosis \\
\hline Positive serology & \\
\hline $\begin{array}{l}\text { Positive IgM ELISA test; positive } \\
\text { serum agglutination test; high titer }\end{array}$ & \\
\hline microscopic agglutination test & 15 \\
\hline $\begin{array}{c}\text { Increased serological microscopic } \\
\text { agglutination test titer }\end{array}$ & 25 \\
\hline
\end{tabular}

